\title{
Demystifying the impact of CEO transformational leadership on firm performance: Interactive roles of exploratory innovation and environmental uncertainty
}

\begin{abstract}
This paper aims to reconcile the inconsistent findings about the effects of CEO transformational leadership (CTL) on firm performance by using upper echelon theory to hypothesize and empirically demonstrate that CTL triggers exploratory innovation in a firm, which in turn has an inverted U-shaped effect on firm performance. In other words, CTL may only lead to better firm performance at moderate levels of exploratory innovation through optimal utilization of a firm's scarce resources and may actually hurt firm performance at higher levels of exploratory innovation because of suboptimal resource utilization. We also show that CTL's most detrimental effect on firm performance occurs when the contingencies of high technology uncertainty and low demand uncertainty are combined. Data from multiple sources within 288 Chinese firms support most of our hypotheses and provide insights into the complex mechanism by which CTL affects firm performance, especially in an increasingly uncertain global economic environment.
\end{abstract}

Keywords: CEO transformational leadership; demand uncertainty; exploratory innovation; firm performance; technology uncertainty 


\section{Introduction}

A firm's ability to adapt quickly to an unpredictable environment is critical to its performance (March, 1991; Levinthal \& March, 1993). In fact, in an increasingly uncertain economic environment, business leaders, especially Chief Executive Officers (CEOs), need to encourage and actualize a quick response to unpredictable market forces (Jansen, Vera, \& Crossan, 2009). Recent research highlights the importance of CEO transformational leadership (CTL) as a set of behaviors by CEOs that motivates their followers to achieve more than originally expected from them (Resick et al., 2009). Transformational behaviors by CEOs also help firms actively initiate exploration of new opportunities and knowledge (Jansen, Vera, \& Crossan, 2009). Transformational CEOs (TCEOs) encourage firms to challenge the status quo and overcome organizational inertia, challenging employees to shift from self-interest to the collective goal of organizational change (Bass \& Avolio, 1993).

Despite growing research on the role of CTL in organizations, there are many inconsistent findings on the effect of CTL on firm performance in the extant literature. Some studies find that CTL helps firms change their existing systems, reconcile conflicts between individual self-interest and collective interest, and adapt to rapidly changing environments more effectively, all of which benefit firm performance (e.g., Aragon-Correa, Garcia-Morales, \& Cordon-Pozo, 2007; Birasnav, 2014; Boehm et al., 2015; Zhu, Chew, \& Spangler, 2005). In contrast, others find that CTL (or its dimension of charisma) has a non-significant effect (e.g., Tosi et al., 2004; Waldman, Javidan, \& Varella, 2004), or even negative effect on firm performance (Ensley, Pearce, \& Hmieleski, 2006). These mixed findings about the relationship between CTL and firm performance represent an important research gap in extant literature and suggest the presence of some potential mediators and/or moderators, which leads to our first research question: Are there any mediators and/or moderators that play a role in the complex relationship between CTL and firm performance? 
Scholars have taken a contingency perspective to reconcile these conflicting findings about the impact of CTL and firm performance, using variables such as environmental uncertainty as a potential moderator of the association between CTL and firm performance (Agle, Sonnenfeld, \& Srinivasan, 2006; Waldman et al., 2001; Waldman, Javidan, \& Varella, 2004), but these studies also show mixed findings. For instance, Waldman et al. (2001, 2004) show a positive effect of the interaction between CEO's charisma (a dimension of CTL) and environmental uncertainty on firm performance, while Agle, Sonnenfeld, and Srinivasan (2006) study found no significant effect. These inconsistent findings about the moderating role of environmental uncertainty between CTL and performance remain unresolved and suggest the possible role of different types of environmental uncertainty, which raises the second research question: Is there any difference in the moderating roles of different types of environmental uncertainly on the influence of CTL and firm performance?

In this paper, we address these two research questions by investigating why and when CTL has the complex (positive vs. negative) effect on firm performance. By so doing, we attempt to extend extant literature of transformational leadership in three ways and make three incremental contributions. First, we provide a nuanced explanation of why CTL can have both positive and negative effect on firm performance, thus advancing our understanding of the complex process of CTL - firm performance relationship. In line with upper echelon theoretical logic, TCEOs should be able to select and implement change-oriented strategies and explore new opportunities to make their firms adaptable to uncertain environments (Jansen, Vera, \& Crossan, 2009; Vera \& Crossan, 2004). For example, TCEOs may be motivated to adopt 'exploratory' innovations (He \& Wong, 2004; March, 1991) to impact firm performance because these may lead to higher returns despite higher risk. In contrast, TCEOs may not adopt 'exploitative' innovations because these only involve refining existing technology and slight changes in the status quo (Vera \& Crossan, 2004; He \& Wong, 2004; 
March, 1991). Hence, this study focuses on exploratory (not exploitative) innovation as the mediator to explain the complex process through which CTL may influence firm performance.

Second, departing from the prior research taking environmental uncertainty as the overarching construct moderating the link between CTL and firm performance (Ensley, Pearce, \& Hmieleski, 2006; Waldman et al., 2001), this study unpacks it into demand and technology uncertainty as two dimensions (Atuahene-Gima \& Li, 2004). In so doing, this study provides a finer-grained explanation of the contingencies, and aims to reconcile the mixed results in the literature about the moderating role of environmental uncertainty. In uncertain environments, causal asymmetry and information complexity become much more salient (Waldman, Javidan, \& Varella, 2004), and hence likely to affect TCEO's preference for exploration innovation strategy. Prior research indicates that demand and technology uncertainty have different implications and requirements for CEO's information processing capability (Atuahene-Gima $\& \mathrm{Li}, 2004)$. Therefore, we select these two sources of environmental uncertainty (demand and technology) as moderating variables in this study to demonstrate the differences in the effects of CTL under different contingencies. In so doing, this study delineates the boundary conditions for the positive and negative effect of CTL and answers the question of when CTL may have a positive or adverse effect on firm performance.

Third, different from the prior studies which primarily examine the adverse effect of transformational leadership at individual level (Eisenbeiss \& Boerner, 2013), this study empirically examines the detrimental effect of CTL on firm performance at the organization level. Even though some research has investigated the harmful impact of transformational leadership on individual's creativity and performance (Eisenbeiss \& Boerner, 2013; Tourish, 2013), it is unclear whether transformational leadership at executive level would also harm firm's performance. Waldman et al. (2001) call for more research on the strategic impact of CTL on firm performance, and contend that transformational leadership at different 
organizational hierarchy has differing implication for performance outcomes. As the leader of the TMT (Hambrick \& Mason, 1984), TCEOs are likely to possess and exercise disproportionate influence compared to the other TMT members, which in turn would have a strategic impact on the firm's performance outcomes (Waldman, Javidan, \& Varella, 2004). Therefore, besides the positive effect of CTL, our study also empirically investigates the likelihood of adverse impact of CTL on firm performance at strategic or organizational level.

This study uses upper echelon theory (Hambrick \& Mason, 1984), which suggests that an executive's specific characteristics and leadership attributes impact firm's strategic choices and outcomes. We argue that as the leader of TMT, TCEOs are likely to possess large amount of internal information during the decision-making process to make strategic choices (e.g., exploratory innovation) to affect firm's outcomes (e.g., firm performance). In addition, TCEOs also need to scan and analyze information from the environment to integrate the internal and external information to make better strategic decisions. Therefore, we select exploratory innovation as the mediator between CTL and firm performance, and demand and technology uncertainty as the moderator between CTL and exploratory innovation.

We begin this paper by reviewing the literature on the development of CTL theory, and then develop our theoretical framework. Next, we develop a conceptual framework and specific hypotheses about the inter-relationships among all these constructs, which we then test using a field survey with data collected from multiple sources within 288 Chinese firms across diverse sectors. Finally, we discuss the findings of this study along with their theoretical contribution and managerial implications, as well as some limitations of this research and useful directions for future research in this area of growing importance.

\section{Theoretical framework}

\subsection{Transformational Leadership}

Transformational leadership represents the behaviors of leaders to inspire their followers 
to perform at a higher than expected level (Resick et al., 2009), a phenomenon that is driven by followers' emotional attachment to the leader and the emotional and motivational arousal that leads them to achieve more than original expected (Hartog, Muijen, \& Koopman, 1997). According to Hater and Bass (1988, p. 695), "The dynamics of transformational leadership involve strong personal identification with the leader, joining in a shared vision of the future, or going beyond the self-interest exchange of rewards for compliance". Transformational leaders are able to expand and raise the motivation of their followers, increase awareness and acceptance of a shared purpose and mission, and inspire them to go beyond their self-interests for the good of the group (Hartog, Muijen, \& Koopman, 1997; Wang, Kim, \& Lee., 2016).

Yammarino and Bass (1990) state that transformational leader stimulates subordinates intellectually, and emphasizes the variances among the followers. Transformational leaders not only affect their individual followers (Newman et al., 2018; $\mathrm{Ng}, 2017$ ), but can also shape their organization culture (Bass \& Avolio, 1993) by highlighting a need for change to create a new shared vision, building commitment of their followers to this vision (Dunne et al., 2016; Hartog, Muijen, \& Koopman, 1997). TCEOs make strategic choices and initiate organizational change that could exerts a strategic impact on the firm's innovation (Nguyen et al., 2017) and performance, which in turn makes the firm more able to adapt to the changing environment (e.g., Chen et al., 2012; Jung, Chow, \& Wu, 2008; Vera \& Crossan, 2004). In addition, recent studies demonstrate that TCEOs can enhance firm performance via developing TMT trust climate (e.g., Lin, Dang, \& Liu, 2016). Thus, it is not surprising to see a positive association between CTL (or its dimension of charisma) and firm performance, as reported in numerous studies over the last few decades (e.g., Elenkov, 2002; Garcia-Morales, García-Morales, Jiménez-Barrionuevo, \& Gutiérrez-Gutiérrez, 2012; Howell, Neufeld, \& Avolio, 2005; Howell \& Avolio, 1993; Lin, Dang, \& Liu, 2016).

Notwithstanding their important contribution, most of these studies realize the positive 
role of CTL, while empirical investigation demonstrates mixed evidence about the relationship between CTL and firm performance. For example, some studies find that CTL (or its dimension of charisma) has a non-significant effect on firm performance (e.g., Tosi et al., 2004; Waldman, Javidan, \& Varella, 2004). In fact, Ensley, Pearce, and Hmieleski (2006) even show a negative association between an entrepreneur's transformational leadership and new venture performance. Hence, the relationship between CTL and firm performance is not straightforward. A recent meta-analysis conducted by Ng (2017) reveals that transformational leadership affect performance outcomes via complex mediating mechanisms, suggesting that the complex mechanism underlying this link needs to be investigated more thoroughly, which leaves the research gap and necessity to further unpack such complex mechanism, because understanding the process of how CTL exerts influence on firm performance can help us know why there are mixed findings in extant literature.

\subsection{Environmental uncertainty}

To reconcile the mixed findings about the relationship between CTL and firm performance, Waldman et al. (2001) show that CEO charisma (as one dimension of CTL) could lead to better firm performance (i.e., net profit margin) in a highly uncertain environment. This finding is corroborated by Ensley, Pearce, and Hmieleski (2006), who show that environmental dynamism positively moderates the relationship between entrepreneur's transformational leadership and new venture performance. These studies suggest that CTL might be more beneficial to firm performance when environment becomes more uncertain. As an exception, Agle, Sonnenfeld, and Srinivasan (2006) show non-significant effects of the interaction between CEO charisma and environmental uncertainty on firm performance, indicating that there is no significant difference of the CTL's effect on firm performance no matter in higher or lower environmental uncertainty. In other words, CTL's effect on firm performance is not dependent on environmental uncertainty. 
These mixed finding on the moderating role of environmental uncertainty further complicate our understanding of the relationship between CTL and firm performance, and raise questions about whether CTL's impact on firm performance is contingent on environment uncertainty. Hence, we need a more nuanced contingency approach to investigate the moderating role of environmental uncertainty on the complex relationship between CTL and firm performance. We argue that one possible reason for the inconsistent findings on the moderating role of environmental uncertainty in CTL-firm performance link, is that prior research takes environmental uncertainty as an overarching construct, and ignoring the different implications of its dimensions, because each dimension represents different meaning and implication (Atuahene-Gima \& Li, 2004), so combining them might causes ambiguity.

\subsection{CTL and exploratory innovation}

CTL includes four dimensions - charisma, inspiration, intellectual stimulation, and individual consideration (Bass, 1985; Vera \& Crossan, 2004). TCEOs help their followers transcend their self-interest for the sake of the larger vision of the organization. They inspire others with their vision, create excitement through their enthusiasm, puncture time-worn assumptions through their resolve to reframe the future, and question tried-and-tested methods. TCEOs like to challenge the status quo and translate change for organizational members, articulating a clear vision to inspire their followers to embrace change, encouraging them to "think out of box", and building self-efficacy and the confidence to take risks and explore something new (Bass \& Avolio, 1993; Judge \& Piccolo, 2004).

TCEOs act as role models of change and challenge, which justifies the social meaning of exploratory innovation for organizational members. During the strategic decision-making process, they lead TMT members to challenge extant strategies that are not adaptable to environmental changes and select the strategy that explores new technology and opportunity in order to exploit an uncertain environment. TCEOs also create a conducive climate through 
a cascading effect (Boehm et al., 2015) that fosters firms' exploratory innovation. Hence, consistent with Jansen, Vera, and Crossan, (2009), we hypothesize that CTL has a positive impact on exploratory innovation:

H1. CTL has a positive effect on exploratory innovation.

\subsection{Curvilinear mediating role of exploratory innovation}

Prior empirical studies demonstrate that exploratory innovation enhances firm performance by creating new knowledge and business opportunity, which improve cash flows and overall firm performance (He \& Wong, 2004). We argue that exploratory innovation, which is legitimized by TCEOs, is more socially acceptable, which in turn motivates organizational members to enhance cohesion and reduce conflicts in the organization, resulting in enhanced firm performance. This line of research focuses on the benefits of exploratory innovation only while ignoring the costs, challenges, and complexities associated with exploratory innovation, which is risky, demanding, and resource-consuming in nature.

We argue that if firms explore too much, they would probably suffer the risk of innovation failure, and consume the organizational scarce resources and cash flow, which would decrease firm performance. This argument is also corroborated by extant literature, which suggests that too much exploratory innovation may lead to excessive consumption of organizational resources (Gupta, Smith, \& Shalley, 2006; Wang \& Li, 2008), resulting in innovation traps and a vicious circle that leads to increased costs and diminished firm performance (Levinthal $\&$ March, 1993). The underlying rationale for this effect is that too much exploratory innovation might over-stretch the a firm's resources and capabilities, thus making it more difficult for the firm to absorb the results of exploratory innovation, and in turn making it difficult for the firm to apply the new product and technology. Besides, too much exploratory innovation generates path dependence, which pushes the firm to depart from its core business, core competences, and core customers, potentially bringing higher risk of failure (Wang \& $\mathrm{Li}$, 
2008). In short, a moderate level of exploratory innovation is optimal for firm performance. Hence, we hypothesize as follows:

H2a. Exploratory innovation has an inverted U-shaped effect on firm performance.

Based on the above hypotheses, we further propose that CTL affects firm performance via the mediating role of exploratory innovation, because TCEOs select the innovation strategy and initiate change and invest resources on exploratory innovation activities (Jansen, Vera, \& Crossan, 2009), which in turn has a positive impact on firm performance. We admit that TCEOs also adopt other strategic measures to impact firm performance, such as initiating strategic change, building organizational culture, establishing management systems, and so on. Exploratory innovation strategy is among one of those mediators for TCEOs to change existing technology domains and transform new products into cash flow and profit. Hence, H2b. Exploratory innovation mediates the positive effect of CTL on firm performance.

\subsection{Moderating roles of demand vs. technology uncertainty}

Environmental uncertainty refers to the rate of change and the uncertainty of change (Dess $\&$ Beard, 1984) and is usually associated with high risk (Waldman et al., 2001). Although environmental uncertainty has been regarded as the objective demonstration of the external environment, it is essentially a perceptual phenomenon, because it reflects the individual's perceived inability to make sense of the direction in which the environment may be changing (Waldman et al., 2001). Prior research demonstrates that an uncertain environment might cause stress and anxiety to organizational members, thus requiring TCEOS to change crises into opportunity for the firm (Ensley, Pearce, \& Hmieleski, 2006; Waldman et al., 2001). We admit environmental uncertainty generates more opportunities for TCEOs to change the status quo and lead the firm out of crisis, however, it also requires TCEO to have the necessary capabilities. TCEOs' capability to make sense of environmental cues and interpret relevant information is crucial to effective strategy making (Hambrick \& Mason, 1984). 
Environmental uncertainty is categorized into technology and demand uncertainty based on its source (Atuahene-Gima \& Li, 2004). Technology information has multiple and ambiguous meanings and is characterized by causal ambiguity associated with sophisticated technological change, which makes it difficult to analyze and understand when strategy making (Atuahene-Gima \& Li, 2004). Consistent with upper echelon theory, when TCEOs adopt exploratory innovation strategy in an environment with high technology uncertainty, high ambiguity and the sophistication of the technology information (Covin, Prescott, \& Slevin, 1990) mean that the success and future direction of technology change is unpredictable; thus, resource allocation for exploratory innovation is more risky.

In contrast, on the costs side, it is much more difficult for TCEOs to enact such information and communicate such information to other TMT members and convince them to accept the exploratory innovation strategy (Daft \& Weick, 1984). In situations with high uncertainty of technological change and unpredictable gain from technological investment, the communication cost amongst TMT members is higher, and the time taken to achieve strategic consensus more prolonged, thus reducing the likelihood of selecting an exploratory innovation strategy. In sum, a high degree of technology uncertainty might reduce the likelihood of TCEOs' strategic orientation to engage in exploratory innovation. Therefore, as follows: H3a. Technology uncertainty negatively moderates the positive effect of CTL on exploratory innovation.

In contrast, demand information is relatively easier to understand and analyze, because through frequent interaction with customers, their implicit demand will eventually be constructed and enacted (Atuahene-Gima \& Li, 2004). Hence, in an environment with high demand uncertainty, the firm's capability to tap into its customers' demands is critical to winning the first-mover advantage in the market, that is, customers' explicit or implicit unsatisfied needs are the firm's potential opportunity to make profit, and the possibility of 
exploring these needs is realistic and applicable via frequent contact between the firm and its customers. Hence, given the likely significant returns of tapping into customer's changing needs, and the firm's capability to satisfy them through providing technology and products, TCEO's confidence to enact and interpret demand information to TMT members when making strategic decisions is strengthened. Moreover, the communication cost within the TMT is lower and the time taken to arrive at the consensus on adopting exploratory innovation is shortened under high demand uncertainly, hence increasing the likelihood of TCEOs adopting exploratory innovation strategy. Accordingly,

H3b. Demand uncertainty positively moderates the positive effect of CTL on exploratory innovation.

Given the components of the environment are always interlinked, firms will be less likely to survive in an industry with only high technological uncertainty or high demand uncertainty. In short, demand uncertainty is likely to be correlated with technological uncertainty. By combining the above arguments, we also posit that when firms are in an environment with high technology uncertainty and low demand uncertainty, the environment is more dominated by uncertain technology in the industry and TCEOs are more likely to focus on technological uncertainty. In such a situation, the prospect of technological change is unclear and highly risky, and the market potential of exploring customer needs is limited, hence TCEOs' propensity to select an exploratory innovation strategy is less because the failure rate is too high. Moreover, it also makes it more difficult for TCEOs to persuade TMT members to accept the strategy to explore new technology, and increase the cost of TMT integration, thus TCEOs have the lowest level of motivation and capability to select an exploratory innovation strategy. Therefore, as follows:

H3c. Demand and technology uncertainty jointly moderate the positive effect of CTL and exploratory innovation, such that it is weakest when the firm faces a high level of technology 
uncertainty and a low level of demand uncertainty.

Figure 1 illustrates our theoretical framework and all the hypotheses.

$<$ Insert Figure 1 about here $>$

\section{Methodology}

\subsection{Research setting and questionnaire design}

Our research setting comprises firms operating in three industries, i.e., information technology industry, manufacturing industry and finance industry in China. Information technology industry and manufacturing industry are undergoing constant industry structure upgrading and innovation capability enhancement, and exploratory innovation is the critical success factor for firms to gain competitive advantage in these industries. Finance industry is also selected because information technology investment is also important to enhance financing system and securities (Jansen, Vera, \& Crossan, 2009). In addition, transition from planned economy to market economy also generates environmental uncertainty in China. Thus, firms in such setting are suitable for testing our hypotheses.

We developed our sampling frame by obtaining firm's lists covering three industries from various sources, such as local industry associations, the website of China's technology commission, the Yellow Pages, and other open economic databases in China. The list includes the name and telephone of the firms and CEOs, the address and founding year of firms, firm's business scope, firm's industry sectors, etc. In total, we obtained 4200 firms as the population from the list, and randomly selected 700 sample firms out of those to ensure sufficient variance in the firm's age for the subsequent survey.

We designed the questionnaire used in this study in three steps. First, we translated wellestablished scales from past research from English to Simplified Chinese (Mandarin) and back into English, using the well-established translation and back-translation procedure to ensure conceptual equivalence (Zhou, Wu, \& Luo, 2007). Second, we conducted in-depth structured 
interviews with CEOs of five Chinese companies to check if all the scales reflected their firms' realistic situation, in order to justify the scales' relevance and completeness for this study. Third, a pilot test was used with groups of senior executives in Beijing. We invited these respondents to offer their feedback and suggestions on the questionnaire's wording, expression, and design. The pilot test revealed that the respondents understood all the items quite well; unless where indicated, all other variables were assessed by the respondents on a five-point Likert scale ( $1=$ strongly disagree, $5=$ strongly agree). Finally, we invited several academics experts to independently assess the questionnaire's validity.

\subsection{Common method variance}

To reduce common method variance (CMV), we gathered data from different respondents within one firm (Podsakoff, MacKenzie, \& Lee, 2003), using the traditional approach to assessing leadership behaviors as perceived by others rather than the leader him/herself (Waldman et al., 2001). Thus, we administered the CEO transformational leadership sub-questionnaire to the Chief Administrative Officers (CAOs) who assist the CEOs in firms' internal administrative affairs, Chief Human Resource Officers (CHROs), and Chief Technological Officers (CTOs). As members of the TMT, these senior executives are engaged in strategic decision making in firms and have frequent interactions with CEOs. Thus, they are all likely to be quite familiar with their CEO transformational leadership style and able to assess it for the purposes of this study.

Similarly, the sub-questionnaires for demand and technology uncertainty were assessed by the CHROs, because, according to our initial interview, they are relatively more knowledgeable about the firms' external environment. This approach also mitigates the CMV issue in this study. Finally, the sub-questionnaires for exploratory innovation were completed by the CTOs, and the questionnaires for firm performance were assessed by the CFOs (Chief Financial Officers) who are more familiar with firm performance. Thus, the separation of the 
data sources could effectively mitigate the CMV. In addition, to test if our results were affected by CMV, we used Harman's single factor analysis. The results indicated that a single factor explained only $23.57 \%$ of the variance, much lower than half of the variance, further suggesting that the CMV was not a major concern in this study.

\subsection{Procedure}

We combined on-site delivery with mail delivery to distribute our questionnaires. We collected data in two municipalities and ten provinces in China. For firms located around the Beijing municipality, we used trained research assistants to conduct on-site survey delivery with the permission of senior executives, which is an effective means to access high-quality data in emerging economies such as China (Zhou, Wu, \& Luo, 2007). We used a simple yet effective procedure, wherein we first made phone calls to the senior executives in the sample firms to introduce our research objectives and the project's relevance to them, in order to seek their permission for participation in our study. If they agreed, we asked trained research assistants to deliver the survey to the respondents in the firm on site. For respondents who were not available, we sent the survey when they were available at a later date.

For firms far away from Beijing, it would have been costly to conduct on-site survey delivery, therefore, with the permission of the senior executives in sampled firms, we mailed the four sub-questionnaires for each firm in different postage-paid envelopes indicating the position title of the respondents, with a return address. Three weeks after the surveys were mailed, we made follow-up phone calls to the potential respondents who had not returned the completed questionnaires, in order to improve our overall response rate. No significant differences in the average scores for all the variables between the two different approaches for data collection show that there may not be any systematic bias between them.

\subsection{Sample}

We obtained responses from 387 firms, and after dropping 60 cases with excessive 
missing data, and 39 cases with unpaired data from different informants, the final sample has 288 firms with an effective response rate of 41.14\%. Following Kanuk and Berenson (1975), we evaluated the potential non-response bias by comparing the difference between early and late respondents, recording the response order of the survey, and found it uncorrelated with either firm age $(r=.04, p=.66)$ or firm size $(r=.07, p=.28)$, hence non-response bias is not a major concern in this study (Cao, Gedajlovic, \& Zhang, 2009; Kanuk \& Berenson, 1975).

In terms of the sample firm's characteristics, average firm age (measured by the number of years since inception) is 10.66 . Average firm size (measured as the total number of employees) is 783 . With regard to ownership, $56.9 \%$ of the firms in our sample are private, $24.2 \%$ international joint ventures, and $18.9 \%$ state-owned. Among the industry segments, the largest is information technology (52.2\%), followed by manufacturing (38.7\%) and finance industry (9.1\%). We found no significant differences in the average scores of all the variables across sub-groups based on firm age, size, ownership, and industry, hence we pooled the data into a single sample with all these as control variables for our subsequent data analysis.

\subsection{Measures}

CEO Transformational leadership (CTL). This scale was adopted from Vera and Crossan (2004), which assessed CEOs rather than middle or lower level leader's transformational leadership, which means it is more appropriate for this study. The scale comprises four dimensions: charismatic leadership, inspirational motivation, intellectual stimulation, and individualized consideration. Each dimension contains three items. As mentioned earlier, we had asked three senior executives (CAO, CTO, CHRO) to assess CTL, to reduce single rater's bias on the perception of leadership behavior. However, such an approach raises concerns about the inter-rate agreement and, therefore, we conducted aggregation analysis before forming the mean value from different sources. For this, we calculated $\mathrm{R}_{\mathrm{wg}}$, ICC (1) and ICC (2), the three most commonly used indices to demonstrate within-team agreement and 
between-team difference (James, 1982). Values of .87, .33 and 0.59 for $\mathrm{R}_{\mathrm{wg}}$, ICC (1) and ICC

(2) respectively are all better than their recommended cut-off values, which justified our aggregation of the transformational leadership scores. A high Cronbach's $\alpha$ (.94) provides evidence of the reliability of this scale.

Exploratory innovation. This five-item scale was derived from Lubatkin et al. (2006) and completed by CTOs. It reflects firm's strategic orientation on exploratory innovation. One item (i.e., my firm actively targets new customer groups) was deleted due to high cross-factor loadings but a high Cronbach's $\alpha(.77)$ shows that the scale is still reliable.

Demand uncertainty. This three-item scale was derived from Atuahene-Gima and Li (2004) and was rated by CHROs. A high Cronbach's $\alpha$ (.83) supports reliability of this scale.

Technology uncertainty. This four-item scale was also derived from Atuahene-Gima and Li (2004) and also rated by CHROs. Cronbach's $\alpha$ (.73) shows acceptable reliability.

Firm performance. This scale was adapted from Li and Atuahene-Gima (2001). We invited CFOs to assess the firm's relative performance ( 1 = much worse, $5=$ much better $)$ compared to its major competitors in their industry. Reliability analysis for firm performance (Cronbach's $\alpha=.71$ ) indicates acceptable reliability for the scale. We relied on relative performance rather than objective measures of firm performance, because most firms in our sample are private firms not listed in the stock market and hence are not legally required to disclose their performance data. Previous studies in similar contexts suggest that when it is difficult to obtain objective and reliable third-party data on the financial performance index, relative firm performance could be an effective substitute for objective performance measures (e.g., Cao, Gedajlovic, \& Zhang, 2009; Li \& Atuahene-Gima, 2001; Lubatkin et al., 2006; Robinson \& Pearce, 1988). Past research also shows that self-reported subjective performance correlates highly significantly with objective measures of firm performance (Robinson \& Pearce, 1988). Therefore, as recommended in past research, we also adopt the self-reported 
relative performance measure in this study. Appendix I shows all the scale items.

Control variables. We controlled for a variety of firm level variables. Firm age was controlled because younger firms tend to become more organic and dynamic than older firms. We also controlled firm size because it indicates a firm's investment in long-term assets, which might drive for new ideas and better competitive position in the future (Lubatkin et al., 2006). As firm ownership ( $1=$ private firm, $0=$ others $)$ and industry sectors $(1=$ IT industry, $0=$ others) are categorical variables, we transformed them into dummy variables. R\&D intensity fosters innovation capability and thus impacts firm performance, hence we used it as a control variable and measured it as the percentage of R\&D investment on sales. Moreover, too much investment in R\&D might jeopardize a firm's future resources and put the firm constantly at high risk and unable to take advantage of the returns of innovation (Wang \& $\mathrm{Li}$, 2008), hence we also included R\&D squared term as a control variable. Finally, according to upper echelon theory, CEO's demographic characteristics reflect their cognitive mode and value, which might influence their strategic choices, therefore, we controlled CEO age, CEO position tenure (number of years since CEO stepped into its position), and CEO education (1 $=$ under high school, $2=$ junior college, 3 = bachelor, $4=$ master, $5=$ doctor and above).

\section{Data Analysis and Results}

\subsection{Measurement model}

We used confirmatory factor analysis (CFA) with structural equation modelling (SEM) to test the validity of all the scales, including the four sub-scales for CEO transformational leadership and the scales for exploratory innovation, demand uncertainty and technology uncertainty and firm performance, resulting in an eight-factor measurement model. We constrained all the items to an 8-factor model, and the results of the CFA in Table 1 indicate that the 8 -factor model achieved a better fit to the data than other nested competing models and all the items also exhibit highly significant standardized loadings. 


\section{$<$ Insert Table 1 about here $>$}

Table 2 presents the descriptive statistics and correlations for the variables in this study. No correlation coefficient is over the .65 threshold level, indicating that the estimations in our model are not likely to be biased by multi-collinearity issues (Tabachnick \& Fidell, 1996).

$$
<\text { Insert Table } 2 \text { about here }>
$$

\subsection{Statistical analysis}

After testing all the scales for their psychometric properties, in terms of their reliability and validity, we tested all the hypotheses using the Ordinary Least Square (OLS) statistical model. As shown for Model 2 in Table 3, CTL has a significant positive effect on exploratory innovation $(b=.33, p<.001)$, suggesting that transformational leadership behavior of CEOs can promote firm's exploratory innovation, thus Hypothesis 1 finds strong support.

\section{$<$ Insert Table 3 about here $>$}

Hypothesis 2a posits an inverted U-shaped relationship between exploratory innovation and firm performance. Model 5 reveals that exploratory innovation has a significant positive effect on firm performance $(b=.20, p<.01)$, however, the squared term of exploratory innovation also has a negative effect on firm performance $(b=-.06, p<.01)$, which indicates an inverted-U effect, suggesting that optimal exploratory innovation is beneficial to firm performance, while too much of it would cause detrimental effect on firm performance, thus lending support to Hypothesis 2a. Next, hypothesis $2 \mathrm{~b}$ proposes that exploratory innovation will mediate the association between CTL and firm performance. Given the inverted U-shaped relationship between exploratory innovation and firm performance, we adopted two approaches to test this possible mediating effect.

In the first approach, we adopted the traditional mediating effect testing procedure proposed by Baron and Kenny (1986). First, by combining the results from Hypothesis 1 and 2a, we find that the significant positive relationship between CTL and firm performance 
becomes weaker (from $\mathrm{b}=.34, p<.001$ in Model 4 to $\mathrm{b}=.25, p<.001$ in Model 5), indicating that exploratory innovation may partially mediate the relationship between CTL and firm performance, which suggests that TCEOs can directly affect firm performance, or partially exert impact on firm performance via adopting exploratory innovation as the mediating means. The second approach to test the curvilinear mediating effect is to adopt the instantaneous indirect effect (denoted as THETA) test proposed by Hayes and Preacher (2010). When the mediating effect is linear, THETA is constant. However, when there is a curvilinear mediating effect, THETA will be a function of the independent variable (see Hayes \& Preacher, 2010, for full details).

$<$ Insert Table 4 about here $>$

Table 4 displays the instantaneous indirect effect (THETA) of CTL on firm performance via the mediating role of exploratory innovation. Following Hayes and Preacher (2010), we took one standard deviation below and above the mean value of the independent variable (e.g., CTL) as the lower and higher level, and found that the THETA in the lower and medium level of CTL is significantly positive respectively $(\mathrm{LLCI}=.02, \mathrm{ULCI}=.14$ at the lower level, and $\mathrm{LLCI}=.01, \mathrm{ULCI}=.10$ at the medium level), while at the higher level, THETA became non-significant $(\mathrm{LLCI}=-.02, \mathrm{ULCI}=.07)$ because 0 exists between LLCI and ULCI. Thus, we can conclude that at the lower and medium levels of CTL, the instantaneous indirect effect of CTL on firm performance is positively significant through the curvilinear mediating role of exploratory innovation, while at higher levels of CTL, its effect on firm performance becomes non-significant. In sum, Hypothesis $2 \mathrm{~b}$ only finds partial support.

Hypothesis 3a posits that demand uncertainty positively moderates the effect of CTL on exploratory innovation and Hypothesis $3 \mathrm{~b}$ posits that technology uncertainty negatively moderates the above relationship. We used multiple moderated regression (MMR) to test these two hypotheses about moderating effects. Following Aiken, West, and Reno (1991), we 
mean-centered the variables and created interaction terms to minimize multicollinearity. The results in Table 5 demonstrate that neither the two-way interaction term of CTL and demand uncertainty $(\mathrm{b}=.02, \mathrm{~ns})$ nor the CTL and technology uncertainty $(\mathrm{b}=.00, \mathrm{~ns})$ are significant, thus Hypothesis $3 \mathrm{a}$ and $3 \mathrm{~b}$ are not supported.

$<$ Insert Table 5 about here $>$

Finally, hypothesis $3 \mathrm{c}$ proposes that the effect of CTL on exploratory innovation will be the lowest when technology uncertainty is high and demand uncertainty is low. Table 5 demonstrates a significant and positive three-way interaction $(b=.07, p<0.01)$ of CTL with demand and technology uncertainty on exploratory innovation. Following Aiken, West, and Reno (1991), we took one standard deviation below and above the mean value of moderators (i.e., demand and technology uncertainty) and plotted the three-way interactive effect in Figure 2. We observe that when technology uncertainty is high and demand uncertainty is low, CTL has the lowest effect (i.e., the slope is negative) on exploratory innovation, suggesting that TCEOs perform worst under the environment characterized by high technology uncertainty and low demand uncertainty. Moreover, under low technology uncertainty and high demand uncertainty, CTL has a positive effect on exploratory innovation, hence demand and technology exert different moderating roles, which justify the separation of the dimensions of environmental uncertainty.

$<$ Insert Figure 2 and 3 about here $>$

\subsection{Post-hoc analysis}

We used a series of post-hoc analysis to further examine our findings, including the three-way interactions and the role of control variables, and to address the potential concerns about reverse causality and endogeneity due to the cross-sectional design of our study. First, the partial mediating role of exploratory innovation between CTL and firm performance indicates that demand and technology uncertainty may also moderate the direct effect of 
transformational leadership on firm performance. In Table 6, the three-way interaction of transformational leadership, demand, and technology uncertainty positively relates to firm performance $(b=.08, p<0.001)$. From the three-way interactive effect in Figure 3 , we observe that CTL has the weakest effect (the slope is negative) on firm performance when technology uncertainty is high and demand uncertainty is low, and the effect of CTL on firm performance is positive when technology demand is low and demand uncertainty is high. These findings are consistent with the pattern of relationships between CTL and exploratory innovation and, thus, help reconcile the inconsistent findings about the moderating role of environmental uncertainty between CTL and firm performance. Second, in order to examine whether our findings are sensitive to the control variables we selected, after removing all the control variables and those with non-significant effects, we found no major changes in our overall results, suggesting that our results are robust to the control variables.

$<$ Insert Table 6 about here $>$

Third, the cross-sectional research design of our study may lead to concerns about reverse causality, wherein firm performance or its interaction with environmental uncertainty might also impact the adoption of CTL. To test this issue, we use the method recommended by Landis and Dunlap (2000), to swap the independent and outcome variables and test this alternate model. If alternate model is insignificant, it indicates that reverse causality is not a major concern. Specifically, we use firm performance as the independent variable and CTL as outcome variable, and test the significance of the interactive impact of firm performance with demand and technology uncertainty on CTL. Our results show that the two-way and three-way interactions of firm performance with demand and technology uncertainty have no significant effects on CTL, hence reverse causality is not a major concern in this study.

Fourth, to further rule out any concerns about endogeneity of the independent and dependent variables in this study, we use commonly accepted instrumental regression model 
to reduce endogeneity (Antonakis et al., 2014; Bascle, 2008). Endogeneity mainly derives from three sources: measurement errors, omitted variables and reverse causality (Bascle, 2008). If the endogeneity is not serious, the reverse causality caused by cross-sectional data will be not a major concern (Antonakis et al., 2014), and instrumental regression model is an effective way to mitigate the endogeneity issue (Bascle, 2008). To begin with, lagged dependent variables are often considered as useful instrumental variables in econometrics (Antonakis et al., 2014), hence we use firm prior performance (compared to the performance of competitors) as the first instrumental variable.

Next, we use location openness as the second instrumental variable, because provinces closer to the coast in China are relatively more open and adopt reform and open-up policies earlier than the other provinces, thus CEOs in these provinces are more open-minded to the changes and willing to take risk. Hence, location openness is related to CTL, but not necessarily with firm performance. Finally, we calculate industry aggregated CTL score by aggregating score of CTL except for the focal firm's CTL score in each industry. According to institutional isomorphism perspective, leadership behavior in specific industry will be learnt and shaped mutually, thus CTL within same industry will be more isomorphic than between industries. Given above logic, industry aggregated CTL score will be closely related to firm CTL, because CTL of other firms in same industry will affect the focal firm's CTL, but not focal firm's performance.

To summarize, we use three instrumental variables in this study; a) firm's past performance (compared with major competitors in the prior three years), b) location openness (a dummy variable defined as 1 if the firm is located in provinces close to coast and 0 for others), and c) industry aggregated CTL score. We use the Limited Information Maximum Likelihood (LIML) estimation method to re-examine our hypothesized model because the results from LIML estimation are robust even with weak instrumental variables. The 
IV_LIML model shows similar results with the results from OLS model, suggesting that endogeneity caused by cross-sectional data is not a major concern in this study (Bascle, 2008).

\section{Discussion}

\subsection{Theoretical contributions}

This study aims to explain the conflicting findings about the impact of CEO transformational leadership on firm performance by examining the complex mechanism of transformational leadership on firm performance, and investigating why and when CTL might benefit or hamper firm performance. The present study shows that the mechanism by which CTL has a positive as well as a negative effect on firm performance, is that exploratory innovation takes a partially curvilinear mediating role between them. Namely, CTL has a direct positive effect on firm performance, while also has an indirect negative effect on firm performance. In terms of contingency of CTL, our results reveal that when firms operate in the environment with high technology uncertainty and low demand uncertainty, CTL has a negative effect on exploratory innovation and it is also detrimental to firm performance.

By investigating the complex mechanisms and contingencies of CTL on firm performance, this study makes three incremental contributions to the transformational leadership literature. First, this study extends the knowledge on the dual roles of transformational leadership at strategic level, thus providing a complete understanding of the positive and negative effect of CTL on firm's performance. Over the past few decades, transformational leadership has attracted significant attention from different research fields (see Judge \& Piccolo, 2004, for a review), and scholars have made numerous efforts to understand transformational leadership at an executive level (e.g., Howell, Neufeld, \& Avolio, 2005; Zhu, Chew, \& Spangler, 2005). However, the majority of the research focuses on the positive effect of transformational leadership while neglecting its negative effect, leaving an incomplete picture of the role of transformational leadership. 
Although Tourish (2013) considers the negative effect of transformational leadership, there is scant empirical study of this phenomenon. For example, Eisenbeiss and Boerner (2013) empirically examine the harmful effect of a leader's transformational leadership on his or her subordinate's creativity, but their study was anchored at the individual level. Thus, it is still unclear whether executive's transformational leadership at strategic level also has the potential to harm firm performance as well as benefit it. Our study demonstrates a positive direct effect as well as a negative indirect effect of CTL on firm performance, thus providing a more complete picture on the complex role of CTL in this process.

Second, this study advances our knowledge of the complex mechanism by which CTL may backfire at an organization level by showing that, besides positive role, CTL can generate a negative effect on firm performance, such that the mediating role of exploratory innovation on firm performance is an inverted U-shaped. We demonstrate that TCEOs are generally likely to adopt exploratory an innovation strategy to enhance their charisma and firm performance, but they also run the risk of investing too many resources, which might deplete the firm's scarce resources and jeopardize firm performance. Hence, CTL would result in a detrimental effect on firm performance, as a result of an indirect curvilinear mediating mechanism. Therefore, this study refines our understanding of the complex relationship between CTL and firm performance.

Third, by categorizing environmental uncertainty into its two dimensions, and comparing their different implications, this study helps to reconcile conflicting findings about the moderating role of environmental uncertainty between CTL and firm performance (e.g., Howell, Neufeld, \& Avolio, 2005; Waldman, Javidan, \& Varella, 2004). Although our hypotheses $3 \mathrm{a}$ and $3 \mathrm{~b}$ about the moderating role of technological uncertainty or demand uncertainty on CTL and exploratory innovation are not supported, their three-way interaction effect is supported. One explanation for the non-significant result might be that firms seldom 
compete and grow in an isolated environment and the components of the environment may interact and reinforce each other. Hence, if a TCEO's attention is just paid on one dimension of the environment, he or she would not fully make sense of the environment, and might select the inappropriate strategy for the firm. TCEOs require complex mindsets and cognition capability to differentiate between the environmental changes derived from different dimensions and to integrate complicated information into a strategic decision-making process.

Our findings show that these two types of uncertainties exert different moderating effects on the link between CTL and exploratory innovation as well as firm performance, thus explaining why previous studies generate inconsistent findings on the moderating role of environmental uncertainty. Thus, our findings not only help reconcile the inconsistent results in the extant literature, but also demonstrate the specific contingencies when CTL may exert a detrimental effect on firm performance and exploratory innovation.

\subsection{Managerial implications}

This study has several important managerial implications. First, its findings can be used by practitioners engaged in the field of leadership development. The job of HR managers is to select and train potential leaders or senior executives. Traditionally, potential leaders who exhibit a transformational leadership style are more likely to be noticed and selected, because they show their charisma, articulate a collective vision, and inspire an intellectual thinking style. However, prior research shows that transformational leaders develop dependence in their followers and reduce the creativity of their subordinates (Eisenbeiss \& Boerner, 2013). Our study shows that firms stress too much transformational leadership development might also initiate too much strategic change or exploratory innovation, exposing the firm to high risk and potentially lower performance. Therefore, when designing the programs, executive recruitment and training programs should consider beneficial and detrimental role of transformational leadership, especially in uncertain environments. 
Second, leadership coaches and consultants should train young managers who aspire to become executives to be consistent with the organization's environmental contingencies. This is important because by the time these young managers are in senior leadership positions, it is difficult to change their behaviors and they may find it difficult to adapt to changing contingencies, such as environmental uncertainty. Our findings reveal that transformational leaders should also be like contingent leaders and their behaviors should align with the firm's environmental uncertainties. Moreover, training programs could be provided to help leaders develop or change their leadership styles, with continuous direction towards the firm's performance goals, as well as including industrial analysts to highlight changing trends in technology development and customer preference. Efforts to train leaders to be aware of environmental change support adaptability in leadership behavior to fit changing contingencies. To conclude, we recommend that transformational leaders need to adjust their behaviors to better adapt to the prevailing environment faced by their firms.

Third, our results have important managerial implications for the firms' multiple stakeholders. For example, from the employee's side, they should follow transformational leaders to break the job routine and enhance their creativity during the process of completing the job. However, they might admire the charisma of transformational leaders and generate overdependence on such leadership, which could hurt their creativity. Thus, employees should be cautious to the detrimental role of transformational leaders in their job settings. From the board director's side, a series of corporate governance mechanisms should be taken to mitigate the potential harmful effect of TCEOs, such as separating the chairman of the board from CEOs, and setting the composite performance measures to assess the CEO's balancing capability to take the organizational changes as well as controlling the associated risk. Besides, from the TMT building perspective, recruiting the TMT members with different leadership behaviors, and bringing the external experts into decision-making process, may help 
counterbalance the detrimental effect of TCEOs when making strategic decisions.

\section{Limitations and Future Research}

This study has some limitations, which suggest some useful directions for future research. First, our data is cross-sectional, which does not allow us to test the causality of the variables in this study. Although we conducted robustness tests and used the IV model to eliminate the concern of reciprocal causality as far as possible, a longitudinal study would be more applicable to examine the causality of the relationship between CTL and firm performance. Therefore, future research may use a longitudinal research design, wherein CTL could be assessed at Time 1, exploratory innovation at Time 2, and firm performance at Time 3.

Second, most of the research on CTL has been conducted in a Western context characterized by individualistic cultural values, whereas our research setting was the Chinese context, which represents collectivistic cultural values. Values play an important role in understanding how transformational leadership (Fu et al., 2010) and national culture might shape a CEO's values. Further studies may investigate whether the findings are valid across cultural contexts and whether cross cultural difference might moderate the relationships.

Third, based on the availability of data, we used subjective performance and innovation measures to capture firms' realistic performance and innovation because the extant literature shows that objective and subjective performance indexes are highly correlated; therefore, future research could select listed firms and combine subjective data from surveys with objective date from annual reports, to further corroborate the robustness of our findings.

Fourth, we select exploratory innovation as one mediating variable to explain the complex mechanism of CTL on firm performance, but there may be other mediators, such as firm strategy, corporate culture, organizational structure, and so on. Meanwhile, there might be other contingency variables that could moderate the relationship between CTL and firm performance, and these mediators and moderators deserve further investigation in the future. 


\section{References}

Agle, B. R., Sonnenfeld, J. A., \& Srinivasan, D. (2006). Does CEO charisma matter? An empirical analysis of the relationship among organizational performance, environmental uncertainty and top management tem perceptions of CEO charisma. Academy of Management Journal, 49(1), 161-174.

Aiken, L. S., West, S. G., \& Reno, R. R. (1991). Multiple regression: Testing and interpreting interactions. Thousand Oaks, CA: Sage Publication, Inc.

Antonakis, J., Bendahan, S., Jacquart, P., \& Lalive, R. (2014). Causality and endogeneity: Problems and solutions. In D. V. Day (Ed.), The Oxford handbook of leadership and organizations (pp. 93-117). New York: Oxford University Press.

Aragon-Correa, J. A., Garcia-Morales, V. J., \& Cordon-Pozo, E. (2007). Leadership and organizational learning's role on innovation and performance: Lessons from Spain. Industrial Marketing Management, 36(3), 349-359.

Atuahene-Gima, K., \& Li, H. (2004). Strategic decision comprehensiveness and new product development outcomes in new technology ventures. Academy of Management Journal, 47(4), 583-597.

Baron, R. M., \& Kenny, D. A. (1986). The moderator-mediator variable distinction in social psychological research: Conceptual, strategic and statistical considerations. Journal of Personality and Social Psychology, 51(6), 1173-1182.

Bascle, G. (2008). Controlling for endogeneity with instrumental variables in strategic management research. Strategic Organization, 6(3), 285-327.

Bass, B. M. (1985). Leadership and performance beyond expectations. New York: Free Press.

Bass, B.M., \& Avolio, B.J. (1993). Transformational leadership and organizational culture. Public Administration Quarterly, 17(1), 112-121.

Birasnav, M. (2014). Knowledge management and organizational performance in the service industry: The role of transformational leadership beyond the effects of transactional leadership. Journal of Business Research, 67(8), 1622-1629.

Boehm, S. A., Dwertmann, D. J. G., Bruch, H., \& Shamir, B. (2015). The missing link? Investigating organizational identity strength and transformational leadership climate as mechanisms that connect CEO charisma with firm performance. Leadership Quarterly, 26(2), 156-171.

Cao, Q., Gedajlovic, E., \& Zhang, H. (2009). Unpacking organizational ambidexterity: Dimensions, contingencies, and synergistic effects. Organization Science, 20(4), 781-796.

Chen, M. Y. C., Lin, C. Y. Y., Lin, H. E., \& McDonough, E. F. (2012). Does transformational leadership facilitate technological innovation? The moderating roles of innovative culture and incentive compensation. Asia Pacific Journal of Management, 29(2), 239-264.

Covin, J. G., Prescott, J. E., \& Slevin, D. P. (1990). The effects of technological sophistication 
on strategic profiles, structure and firm performance. Journal of Management Studies, $27(5), 485-508$.

Daft, R. L., \& Weick, K. E. (1984). Toward a model of organizations as interpretation systems. Academy of Management Review, 9(2), 284-295.

Dess, G. G., \& Beard, D. W. (1984). Dimensions of organizational task environments. Administrative Science Quarterly, 29(1), 52-73.

Dunne, T. C., Aaron, J. R., McDowell, W. C., Urban, D. J., \& Geho, P. R. (2016). The impact of leadership on small business innovativeness. Journal of Business Research, 69(11), 4876-4881.

Eisenbeiss, S. A., \& Boerner, S. (2013). A double-edged sword: Transformational leadership and individual creativity. British Journal of Management, 24(1), 54-68.

Elenkov, D. S. (2002). Effects of leadership on organizational performance in Russian companies. Journal of Business Research, 55(6), 467-480.

Ensley, M. D., Pearce, C. L., \& Hmieleski, K. M. (2006). The moderating effect of environmental dynamism on the relationship between entrepreneur leadership behavior and new venture performance. Journal of Business Venturing, 21(2), 243-263.

Fu, P. P., Tsui, A. S., Liu, J., \& Li, L. (2010). Pursuit of whose happiness? Executive leaders' transformational behaviors and personal values. Administrative Science Quarterly, 55(2), 222-254.

García-Morales, V. J., Jiménez-Barrionuevo, M. M., \& Gutiérrez-Gutiérrez, L. (2012). Transformational leadership influence on organizational performance through organizational learning and innovation. Journal of Business Research, 65(7), 1040-1050.

Gupta, A. K., Smith, K. G., \& Shalley, C. E. (2006). The interplay between exploration and exploitation. Academy of Management Journal, 49(4), 693-706.

Hambrick, D. C., \& Mason, P. A. (1984). Upper echelon: The organization as a reflection of its top managers. Academy of Management Review, 9(2), 193-206.

Hartog, D. N., Muijen, J. J., \& Koopman, P. L. (1997). Transactional versus transformational leadership: An analysis of the MLQ. Journal of Occupational and Organizational Psychology, 70(1), 19-34.

Hater, J. J., \& Bass, B. M. (1988). Superiors' evaluations and subordinates' perceptions of transformational and transactional leadership. Journal of Applied Psychology, 73(4), 695-702.

Hayes, A. F., \& Preacher, K. J. (2010). Quantifying and testing indirect effects in simple mediation models when the constituent paths are nonlinear. Multivariate Behavioral Research, 45(4), 627-660.

He, Z. L., \& Wong, P. K. (2004). Exploration vs. exploitation: An empirical test of the ambidexterity hypothesis. Organization Science, 15(4), 481-494. 
Howell, J. M., \& Avolio, B. J. (1993). Transformational leadership, transactional leadership, locus of control and support for innovation: Key predictors of consolidated business unit performance. Journal of Applied Psychology, 78(6), 891-902.

Howell, J. M., Neufeld, D. J., \& Avolio, B. J. (2005). Examining the relationship of leadership and physical distance with business unit performance. Leadership Quarterly, 16(2), 273-285.

James, L. R. (1982). Aggregation bias in estimates of perceptual agreement. Journal of Applied Psychology, 67(2), 219-229.

Jansen, J. J. P., Vera, D., \& Crossan, M. (2009). Strategic leadership for exploration and exploitation: The moderating role of environmental dynamism. Leadership Quarterly, 20(1), 5-18.

Judge, T. A., \& Piccolo, R. F. (2004). Transformational and transactional leadership: A meta-analytic test of their relative validity. Journal of Applied Psychology, 89(5), 755-768.

Jung, D. I., Chow, C., \& Wu, A. (2008). Toward understanding the direct and indirect effects of CEOs' transformational leadership on firm innovation. Leadership Quarterly, 19(5), 582-594.

Kanuk, L., \& Berenson, C. (1975). Mail surveys and response rates: A literature review. Journal of Marketing Research, 12(4), 440-453.

Landis, R. S., \& Dunlap, W. P. (2000). Moderated multiple regression tests are criterion specific. Organizational Research Methods, 3(3), 254-266.

Levinthal, D. A., \& March, J. G. (1993). The myopia of learning. Strategic Management Journal, 14(S2), 95-112.

Li, H. Y., \& Atuahene-Gima, K. (2001). Product innovation strategy and the performance of new technology ventures in China. Academy of Management Journal, 44(6), 1123-1134.

Lin, H. C., Dang, T. T. H., \& Liu, Y. S. (2016). CEO transformational leadership and firm performance: A moderated mediation model of TMT trust climate and environmental dynamism. Asia Pacific Journal of Management, 33(4), 981-1008.

Lubatkin, M. H., Simsek, Z., Ling, Y., \& Veiga, J. F. (2006). Ambidexterity and performance in small-to-medium-sized firms: The pivotal role of top management team behavioral integration. Journal of Management, 32(5), 646-672.

March, J. G. (1991). Exploration and exploitation in organizational learning. Organization Science, 2(1), 71-87.

Newman, A., Herman, H. M., Schwarz, G., \& Nielsen, I. (2018). The effects of employees' creative self-efficacy on innovative behavior: The role of entrepreneurial leadership. Journal of Business Research, 89 (Aug), 1-9.

Nguyen, T. T., Mia, L., Winata, L., \& Chong, V. K. (2017). Effect of transformationalleadership style and management control system on managerial performance. Journal of Business Research, 70(Jan), 202-213. 
Ng, T. W. (2017). Transformational leadership and performance outcomes: Analyses of multiple mediation pathways. Leadership Quarterly, 28(3), 385-417.

Podsakoff, P. M., MacKenzie, S. B., \& Lee, J. Y. (2003). Common method biases in behavioral research: A critical review of the literature and recommended remedies. Journal of Applied Psychology, 88(5), 879-903.

Resick, C. J., Whitman, D. S., Weingarden, S. M., \& Hiller, N. J. (2009). The bright-side and the dark-side of CEO personality: Examining core self-evaluations, narcissism, transformational leadership, and strategic influence. Journal of Applied Psychology, 94(6), 1365-1381.

Robinson, R. B., \& Pearce, J. A. (1988). Planned patterns of strategic behavior and their relationship to business unit performance. Strategic Management Journal, 9(1), 43-60.

Tabachnick, B. G., \& Fidell, L. S. (1996). Using Multivariate Statistics (3rd ed.). New York: Harper Collins.

Tosi, H. L., Misangyi, V. F., Fanelli, A., Waldman, D. A., \& Yammarino, F. J. (2004). CEO charisma, compensation, and firm performance. Leadership Quarterly, 15(3), 405-420.

Tourish, D. (2013). The dark side of transformational leadership: A critical perspective. New York, NY: Routledge.

Vera, D., \& Crossan, M. (2004). Strategic leadership and organizational learning. Academy of Management Review, 29(2), 222-240.

Waldman, D. A., Javidan, M., \& Varella, P. (2004). Charismatic leadership at the strategic level: A new application of upper echelons theory. Leadership Quarterly, 15(3), 335-380.

Waldman, D. A., Ramirez, G. G., House, R. J., \& Puranam, P. (2001). Does leadership matter? CEO leadership attributes and profitability under conditions of perceived environmental uncertainty. Academy of Management Journal, 44(1), 134-143.

Wang, H., \& Li, J. (2008). Untangling the effects of overexploration and overexploitation on organizational performance: The moderating role of environmental dynamism. Journal of Management, 34(5), 925-951.

Wang, X. H. F., Kim, T. Y., \& Lee, D. R. (2016). Cognitive diversity and team creativity: Effects of team intrinsic motivation and transformational leadership. Journal of Business Research, 69(9), 3231-3239.

Yammarino, F. J. \& Bass, B.M. (1990). Transformational leadership and multiple levels of analysis. Human Relations, 43(10), 975-995.

Zhou, L., Wu, W. P., \& Luo, X. (2007). Internationalization and the performance of born-global SMEs: The mediating role of social networks. Journal of International Business Studies, 38(4), 673-690.

Zhu, W., Chew, I. K., \& Spangler, W. D. (2005). CEO transformational leadership and organizational outcomes: The mediating role of human-capital-enhancing human resource management. Leadership Quarterly, 16(1), 39-52 


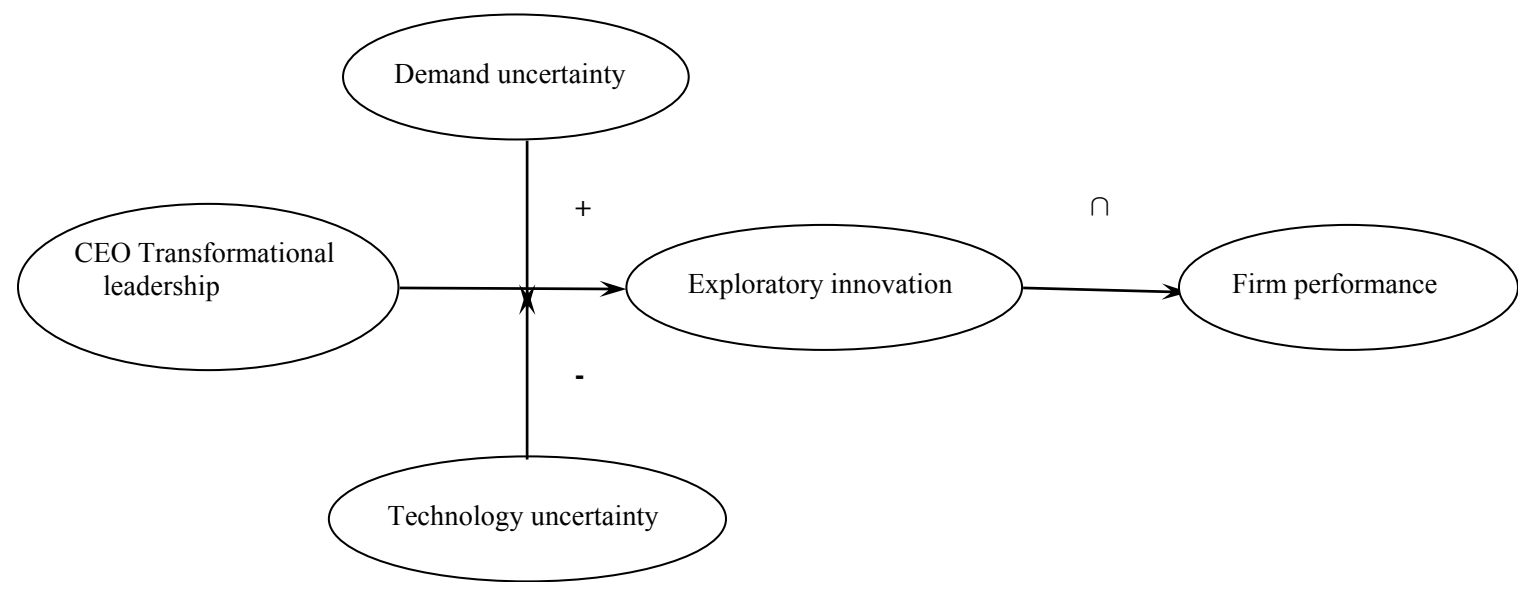

Fig. 1. Hypothesized model. 


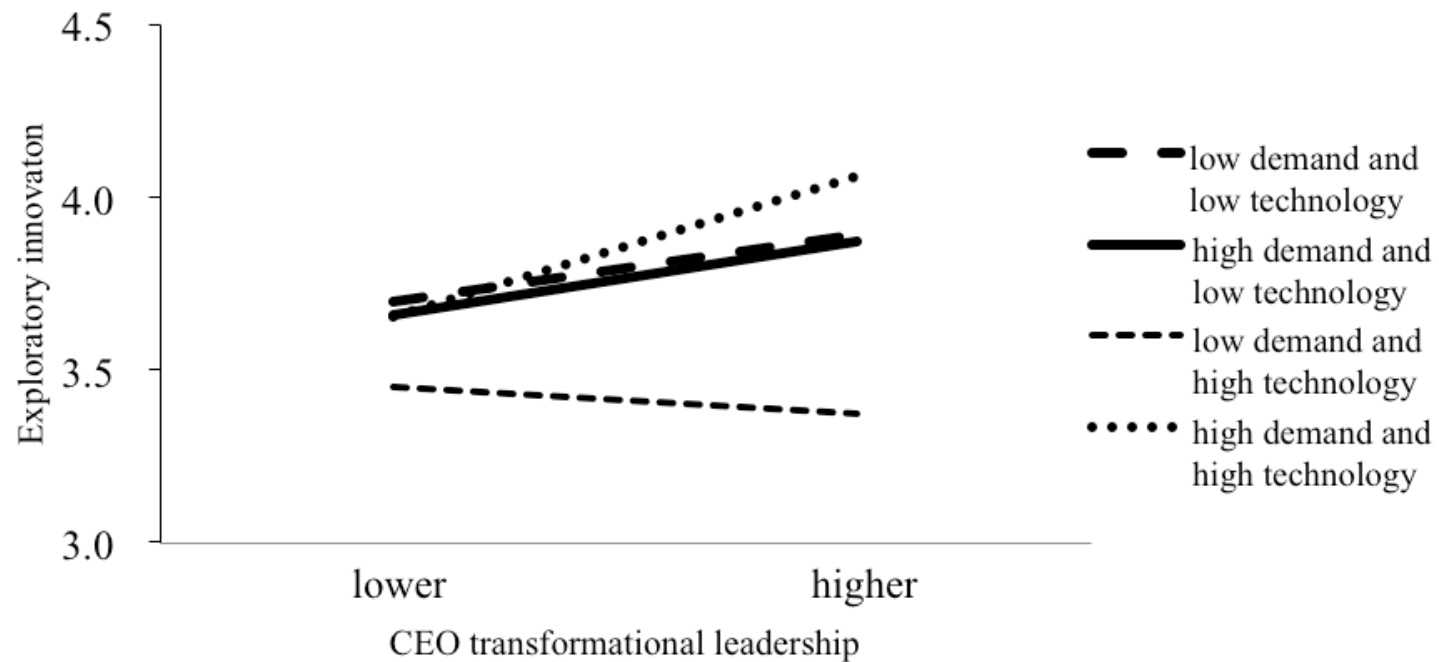

Fig 2. Three-way interactive effect of CTL, demand uncertainty, and technology uncertainty on exploratory innovation. 


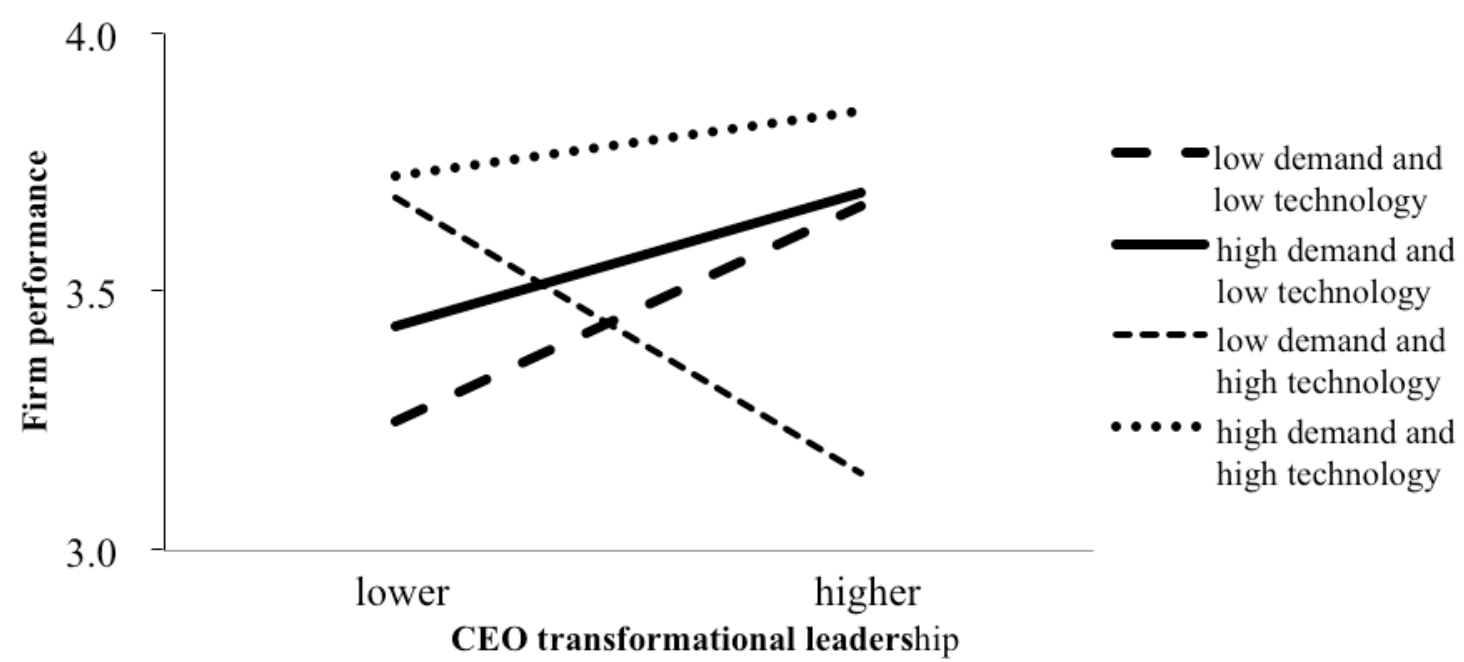

Fig. 3. Three-way interactive effect of CTL, demand uncertainty and technology uncertainty on firm performance. 
Table 1

The CFA Results of the Variables in This Study

\begin{tabular}{lcccccc}
\hline Models & Chi2 & df & Chi2/df & RMSEA & CFI & TLI \\
\hline 8-factor baseline model & 628.419 & 377 & 1.666 & 0.047 & 0.933 & 0.923 \\
7-facor nested model & 882.044 & 384 & 2.297 & 0.066 & 0.868 & 0.851 \\
4-factor nested model & 1091.892 & 399 & 2.736 & 0.076 & 0.816 & 0.800 \\
1-factor model & 1964.292 & 405 & 4.850 & 0.114 & 0.587 & 0.556
\end{tabular}

Note. 7-factor model is formed by combining technology uncertainty and demand uncertainty into one factor; 4-factor model is formed by further combining the four dimensions of transformational leadership into one factor; 1 -factor model is formed by combining all items into one factor. 
Table 2

Mean, Standard Deviations and Zero-order Correlations

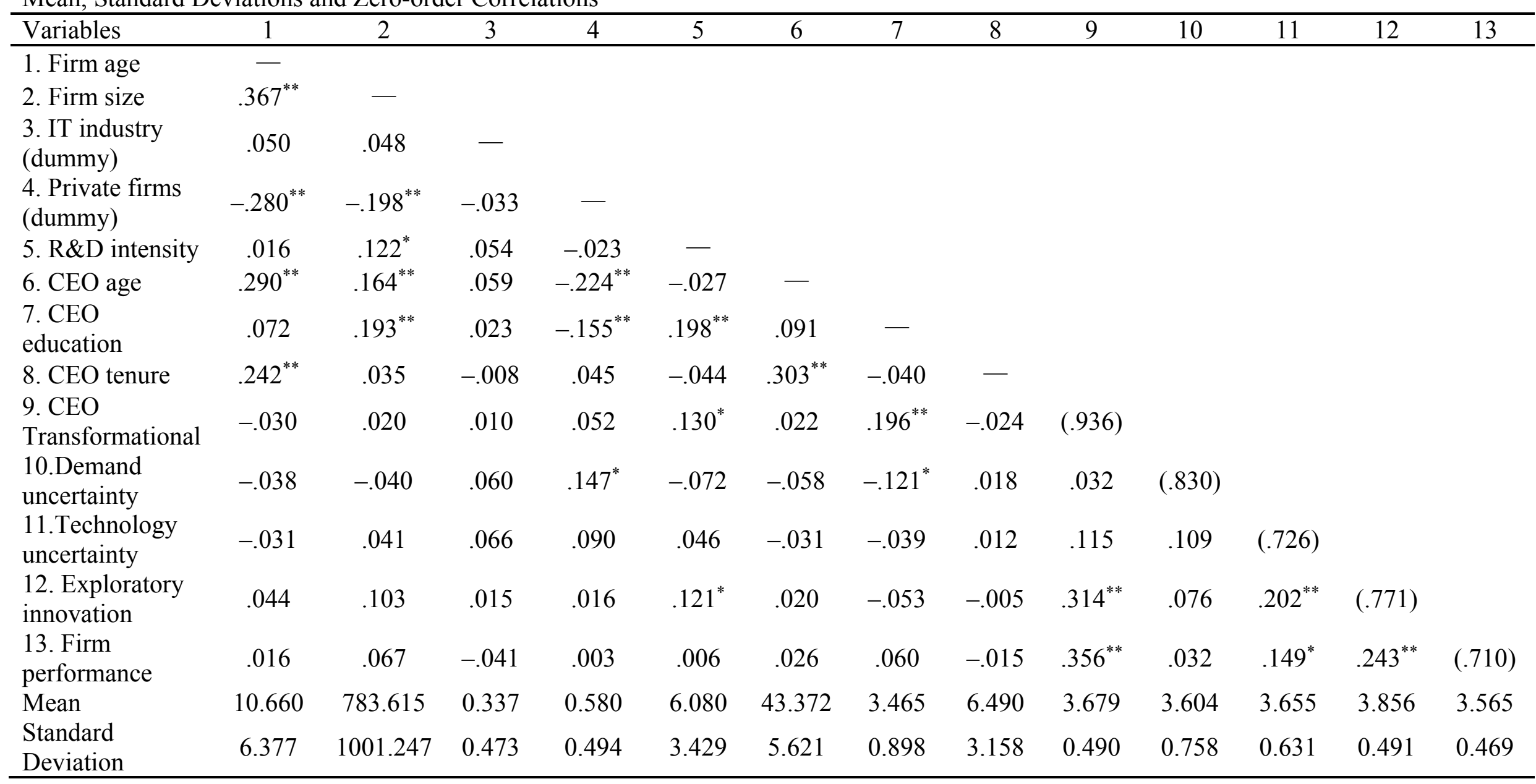

Note. ${ }^{*} p<.05 ;{ }^{* *} p<0.01$. Reliability value is in the parenthesis on the diagonal. 
Table 3

Mediating Effect of Exploratory Innovation between CEO Transformational Leadership and Firm Performance

\begin{tabular}{|c|c|c|c|c|c|c|c|c|c|c|}
\hline & \multicolumn{4}{|c|}{ Exploratory innovation } & \multicolumn{6}{|c|}{ Firm performance } \\
\hline (Controls) & $\mathrm{Mod}$ & el 1 & $\mathrm{Mod}$ & 12 & $\mathrm{Mod}$ & el 3 & $\mathrm{Moc}$ & & Model 5 & \\
\hline Constant & $3.627 * * *$ & $(0.303)$ & $2.600 * * *$ & $(0.340)$ & $3.305 * * *$ & $(0.291)$ & $2.242 * * *$ & $(0.323)$ & $1.824 * * *$ & $(0.348)$ \\
\hline Firm age & 0.003 & $(0.005)$ & 0.003 & $(0.005)$ & 0.001 & $(0.005)$ & 0.001 & $(0.005)$ & 0.002 & $(0.005)$ \\
\hline Firm size $(\log )$ & 0.029 & $(0.033)$ & 0.032 & $(0.032)$ & 0.018 & $(0.032)$ & 0.021 & $(0.030)$ & 0.016 & $(0.029)$ \\
\hline IT industry (dummy) & 0.003 & $(0.062)$ & 0.005 & $(0.058)$ & -0.052 & $(0.059)$ & -0.051 & $(0.056)$ & -0.060 & $(0.054)$ \\
\hline Private firms (dummy) & 0.038 & $(0.063)$ & 0.009 & $(0.060)$ & 0.031 & $(0.061)$ & 0.002 & $(0.057)$ & 0.009 & $(0.056)$ \\
\hline R\&D intensity & $0.022 *$ & $(0.009)$ & $0.016 \dagger$ & $(0.009)$ & 0.005 & $(0.009)$ & -0.001 & $(0.008)$ & -0.008 & $(0.008)$ \\
\hline$R \& D$ intensity squared & -0.038 & $(0.033)$ & -0.021 & $(0.032)$ & $-0.072 *$ & $(0.032)$ & $-0.055 \dagger$ & $(0.030)$ & -0.035 & $(0.030)$ \\
\hline CEO age & 0.002 & $(0.006)$ & 0.001 & $(0.005)$ & 0.003 & $(0.005)$ & 0.001 & $(0.005)$ & 0.001 & $(0.005)$ \\
\hline CEO education & -0.050 & $(0.034)$ & $-0.084^{*}$ & $(0.033)$ & 0.029 & $(0.032)$ & -0.007 & $(0.031)$ & 0.007 & $(0.031)$ \\
\hline $\begin{array}{l}\text { CEO tenure } \\
\text { (Independent) }\end{array}$ & -0.004 & $(0.010)$ & -0.003 & $(0.009)$ & -0.004 & $(0.010)$ & -0.003 & $(0.009)$ & -0.002 & $(0.009)$ \\
\hline $\begin{array}{l}\text { CEO transformational } \\
\text { leadership } \\
\text { (Mediators) }\end{array}$ & & & $0.328 * * *$ & $(0.058)$ & & & $0.339 * * *$ & $(0.055)$ & $0.252 * * *$ & $(0.058)$ \\
\hline Exploratory innovation & & & & & & & & & $0.203 * *$ & $(0.060)$ \\
\hline $\begin{array}{l}\text { Exploratory innovation } \\
\text { squared }\end{array}$ & & & & & & & & & $-0.060 * *$ & $(0.020)$ \\
\hline$F$ & 1.011 & & $4.208 * * *$ & & 0.819 & & $4.624 * * *$ & & $5.336 * * *$ & \\
\hline$\Delta R^{2}$ & 0.032 & & $0.100 * * *$ & & 0.026 & & $0.117 * * *$ & & $0.046^{* *}$ & \\
\hline
\end{tabular}

Note. $\mathrm{n}=288 ; \dagger p<.10 ; * p<.05 ; * * p<.01 ; * * * p<.001 ;$ Unstandardized coefficient values are reported, and standard errors are in parenthesis. 
Table 4

Instantaneous Indirect Effect (THETA) of CEO Transformational Leadership on Firm Performance at Different Level of CEO Transformational Leadership

\begin{tabular}{lllll}
\hline CEO Transformational leadership & THETA & SE & LL CI & UL CI \\
\hline Lower level (3.189) & .064 & .028 & .023 & .135 \\
Medium level (3.679) & .045 & .021 & .010 & .096 \\
Higher level (4.169) & .026 & .021 & -.016 & .068 \\
\hline
\end{tabular}


Table 5

Three-way Effect of CEO Transformational Leadership, Demand Uncertainty and Technology Uncertainty on Exploratory Innovation

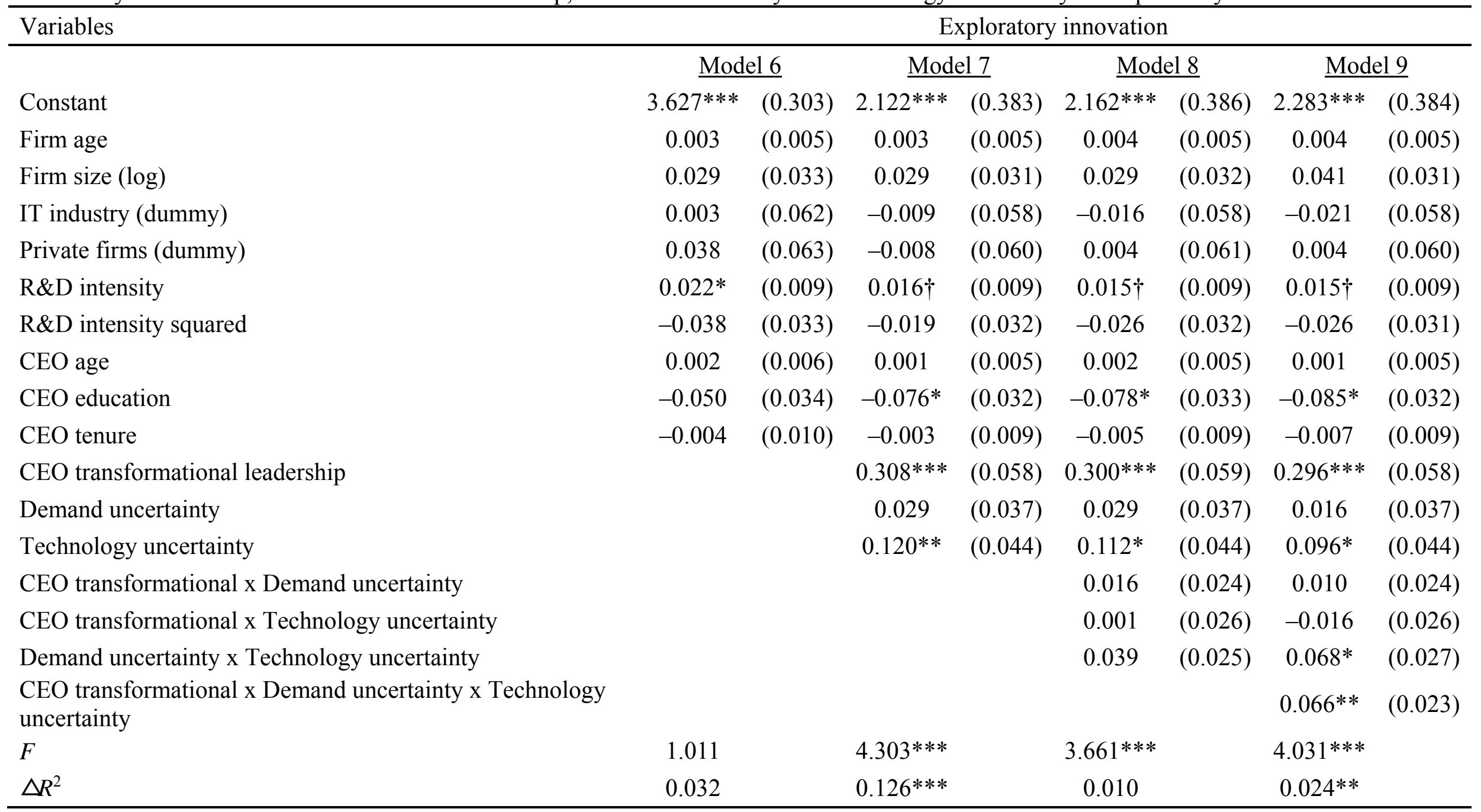

Note. $\mathrm{n}=288 ; \dagger p<.10 ;{ }^{*} p<.05 ;{ }^{* *} p<.01 ; * * * p<.001 ;$ Unstandardized coefficient values are reported, and standard errors are in parenthesis. 
Table 6

The Three-way Effect of CEO Transformational Leadership, Demand Uncertainty and Technology Uncertainty on Firm Performance

\begin{tabular}{|c|c|c|c|c|c|c|c|c|}
\hline \multirow{3}{*}{$\begin{array}{l}\text { Variables } \\
\text { Constant }\end{array}$} & \multicolumn{8}{|c|}{ Firm performance } \\
\hline & \multicolumn{2}{|c|}{ Model 10} & \multicolumn{2}{|c|}{ Model 11} & \multicolumn{2}{|c|}{ Model 12} & \multicolumn{2}{|c|}{$\underline{\text { Model } 13}$} \\
\hline & $3.305 * * *$ & $(0.291)$ & $1.963 * * *$ & $(0.367)$ & $1.853 * * *$ & $(0.367)$ & $1.996 * * *$ & $(0.361)$ \\
\hline Firm age & 0.001 & $(0.005)$ & 0.001 & $(0.005)$ & 0.000 & $(0.005)$ & 0.000 & $(0.005)$ \\
\hline Firm size & 0.018 & $(0.032)$ & 0.019 & $(0.030)$ & 0.022 & $(0.030)$ & 0.037 & $(0.030)$ \\
\hline IT industry & -0.052 & $(0.059)$ & -0.059 & $(0.056)$ & -0.058 & $(0.055)$ & -0.063 & $(0.054)$ \\
\hline Private firms & 0.031 & $(0.061)$ & -0.007 & $(0.058)$ & -0.032 & $(0.058)$ & -0.031 & $(0.057)$ \\
\hline $\mathrm{R} \& \mathrm{D}$ intensity & 0.005 & $(0.009)$ & -0.002 & $(0.008)$ & 0.000 & $(0.008)$ & 0.000 & $(0.008)$ \\
\hline $\mathrm{R} \& \mathrm{D}$ intensity squared & $-0.072^{*}$ & $(0.032)$ & $-0.054 \uparrow$ & $(0.030)$ & -0.046 & $(0.030)$ & -0.046 & $(0.030)$ \\
\hline CEO age & 0.003 & $(0.005)$ & 0.001 & $(0.005)$ & 0.002 & $(0.005)$ & 0.001 & $(0.005)$ \\
\hline CEO education & 0.029 & $(0.032)$ & -0.003 & $(0.031)$ & -0.004 & $(0.031)$ & -0.012 & $(0.030)$ \\
\hline CEO tenure & -0.004 & $(0.010)$ & -0.003 & $(0.009)$ & -0.003 & $(0.009)$ & -0.006 & $(0.009)$ \\
\hline CEO transformational leadership & & & $0.326^{* * *}$ & $(0.055)$ & $0.345^{* * *}$ & $(0.056)$ & $0.341 * * *$ & $(0.055)$ \\
\hline Demand uncertainty & & & 0.003 & $(0.035)$ & 0.010 & $(0.035)$ & -0.006 & $(0.035)$ \\
\hline Technology uncertainty & & & $0.086^{*}$ & $(0.042)$ & $0.088 *$ & $(0.042)$ & 0.069 & $(0.042)$ \\
\hline CEO transformational leadership x Demand uncertainty & & & & & 0.028 & $(0.023)$ & 0.021 & $(0.022)$ \\
\hline $\begin{array}{l}\text { CEO transformational leadership x Technology } \\
\text { uncertainty }\end{array}$ & & & & & -0.008 & $(0.025)$ & -0.028 & $(0.025)$ \\
\hline Demand uncertainty x Technology uncertainty & & & & & $-0.066^{* *}$ & $(0.024)$ & -0.032 & $(0.025)$ \\
\hline $\begin{array}{l}\text { CEO transformational leadership x Demand uncertainty } \\
\mathrm{x} \text { Technology uncertainty }\end{array}$ & & & & & & & $0.078 * * *$ & $(0.022)$ \\
\hline$F$ & 0.819 & & $4.240 * * *$ & & $4.040 * * *$ & & $4.747 * * *$ & \\
\hline$\triangle R^{2}$ & 0.026 & & $0.130 * * *$ & & $0.026^{*}$ & & $0.037 * * *$ & \\
\hline
\end{tabular}

Note. $\mathrm{n}=288 ; \dagger p<.10 ;{ }^{*} p<.05 ;{ }^{* *} p<.01 ; * * * p<.001$; Unstandardized coefficient values are reported, and standard errors are in parenthesis 